\title{
QUALITATIVE ANALYSIS OF LEAN TOOLS IN THE CONSTRUCTION SECTOR IN COLOMBIA
}

\author{
Fran M. Castiblanco', Ivonne A. Castiblanco², and Joan P. Cruz ${ }^{3}$
}

\begin{abstract}
This descriptive research identifies the lean tools applied worldwide in the supply chain of housing construction recognizing which are the most common tools across different countries, the least explored and which tools have the most reception in Colombia.

Through a literary review of 84 academic papers from 22 countries, 254 mentions of 30 lean tools were detected, developing a qualitative content analysis from identified trends of the main differences and similarities in the adoption of lean construction (LC) in Colombia, Latin America and the different continents.

The results derived from a Pareto chart and an affinity analysis in which lean tools were reduced to 23 categories, show that the main practices of lean manufacturing and lean construction are Last Planner System, Building Information Models, Visual Management, among others.

This study is part of a subsequent project that will take the conclusions of this qualitative analysis to suggest a guiding tool (based on the continuous improvement tools found) that correlates applicable lean approaches with the main actors of the supply chain of high value housing projects in Bogotá.

Taking into account the research gap found, this study could serve as a basis for lean construction studies in countries similar to Colombia.
\end{abstract}

\section{KEYWORDS}

Affinity analysis, last planner system, lean construction, Pareto chart, visual management.

\section{INTRODUCTION}

The construction sector in Colombia has become, in recent years, in a considerable contributor to the country's income, thus actively contributing to the Colombian economy. Revista Dinero (2018) documented in one of its publications that the real estate and building market, after being one of the most affected industries during 2017, felt an improvement in 2018 due to the greater disposition of households to invest in

1 Master Student, Industrial Engineering. Escuela Colombiana de Ingeniería, Carrera 45 No. 205-59, Bogotá, Colombia, Phone +57 31339890 21, fran.castiblanco@ mail.escuelaing.edu.co

2 Professor, Industrial Engineering Department, Escuela Colombiana de Ingeniería, Carrera 45 No. 205-59, Bogotá, Colombia, Phone +57 30571278 13, ivonne.castiblanco@escuelaing.edu.co

3 Professor, Industrial Engineering Department, Escuela Colombiana de Ingeniería, Carrera 45 No. 205-59, Bogotá, Colombia, Phone +57 (1) 6683600 ext. 278 joan.cruz@escuelaing.edu.co 
real estate and the rebound of the offer, projecting the industry firm and constant, being one of the best in Latin America ${ }^{4}$.

However, despite its importance in the national economy, this industry has the least technological progress and development at both a national and international level in comparison with other Latin American countries ${ }^{5}$. To reduce this disadvantage, methodologies focused on improving the planning and monitoring processes have been studied, offering tools with easier decision making, mitigation of risks and reduction of time and costs. Lean thinking tools help the efficient planning of activities in productive systems, such as construction, and the reduction or elimination of waste.

Porras, Sánchez and Galvis (2014) affirm that in Latin America the countries that show advances in the use and study of lean construction are Brazil, Chile, Peru and Colombia. Unlike United States and Europe, where lean construction is part of the curriculum in civil engineering related careers, in Colombia lean construction has been studied and practiced in private sector, while at universities there have not been advances on the subject. In Latin America, the country where LC is part of the civil engineering curriculum is Chile ${ }^{6}$.

The above shows the academic gap exist between Colombia and European, Asian or North American countries and the scientific relevance of this type of researches. In fact, only about $6 \%$ of the sources consulted in this investigation are from Colombian and $37 \%$ are from Latin America.

At present, the lean implementations in Colombian construction companies are not widely known and nowadays most of these companies present problems due to noncompliance of real estate deliveries to clients. This evidences the need for the implementation of lean tools in construction to exercise control over the unnecessary factors that generate cost overruns, achieving savings in financial and administration costs, quality in the final product and greater profitability.

If we review the great acceptance that lean practices have had in the world and the proven cases of continuous improvement that have arisen with the implementation of lean thinking tools, and starting from the fact that lean construction is a philosophy that encompasses some approaches of lean thinking, that does not obey an order or a set of fixed rules to be implemented and that its application can be adapted according to the needs and objectives of each company and each project, it is worth reviewing the tools that can be implemented in the construction and check the applicability of lean construction in the supply chain of this sector.

Taking the problem described above, this paper develops a review of the literature to examine the existing knowledge about lean approaches implemented and their characteristics in the construction industry. As a result, a theoretical framework is

4 According to National Administrative Department of Statistics (DANE), the construction of buildings currently generates annual investments of $\$ 77$ billion and contributes $\$ 46$ billion to the national economy. However, the construction sector continues to contract despite the progressive economic recovery of the country (Revista Dinero, August 30, 2018).

5 A report from The Economist Newspaper assures South America in general has a low productivity for every hour worked in construction sector. Even so, the cases of Chile and Argentina stand out as two countries with low growth, while Colombia, Brazil and Mexico have regressed (World Economic Forum, October 25, 2018).

6 In Europe there are already construction companies implementing lean construction. At the Polytechnic University of Valencia there are 2 master's degrees that include the Lean Construction subject since 2012 (El Constructor Newspaper, October 27, 2017). 
proposed playing a decisive role in the formulation of a global guiding tool that adapts to the supply chain of high value housing projects in Bogotá (understood as a guiding tool to the set of the different selected lean thinking tools that apply to the chain), and which will be the basis for further research studies such as the implementation and evaluation of that methodology or the creation of others.

\section{COLOMBIAN CONTEXT}

As mentioned by Araque et al., (2017), civil construction sector in Colombia is one of the main development axes for multiple families linked to this industry, representing an important national economic proportion. However, the characteristics of the workers and the working conditions of the sector have demonstrated the need for continuous improvement and evolution in search of formalization and technification of the associated activities ${ }^{7}$.

The conventional system in Colombia to plan and execute construction works differs from lean thinking, that is, there are currently few companies that implement this work philosophy (Rojas, et al., 2017).

According to a document issued by Revista Dinero (2018), a good future is predicted for this economic sphere in Colombia because of the positive change in the building activity thanks to the development in terms of access to housing and nonresidential and industrial construction, among others. The progress of the sector has had satisfactory effects in terms of economy, generation of employment and reduction of the housing deficit.

In Colombia, unfortunately, most constructions regardless the type are carried out with poor planning, due to incomplete designs, imprecise budgets, disarticulated schedules, non-assertive communication among the different parties involved, absence of internal coordination, confusing instructions, weaknesses in business philosophy, lack of supervision, etc., that in most cases leads to an increase in costs and delays in the different construction activities.

Additionally, most traditional construction processes are carried out manually, which means that the productivity of each process depends mainly on the organization of the activities and the performance and experience of each worker, making the "productivity" into a critical point.

The Colombian Association of Systems Engineers (ASIS), on its website (2019), affirms lean construction acts on construction companies, in each process, adjusting deadlines, resulting in more quality, and ensuring deliveries without delay. Colombian construction companies must adopt lean because in a crisis scenario in the region, with scarce financial resources, only companies that apply this philosophy will be able to produce more and better using the same resources. Regarding compliance with deadlines, today the construction companies can not delay more, because it has a direct impact on the utility of the project, and it would cause fines and sanctions.

Research on lean construction in Colombia began in 2002 (Botero and Álvarez, 2004), where the tools Value Stream Mapping (VSM), Last Planner System (LPS), Kanban, Building Information Modeling (BIM), 5S, Pull Planning System (PPS), Just in Time (JIT), Jidoka, Kaizen, among others, have been adopted. According to Pons

7 Construction is, worldwide, the industry with the least amount of increase in productivity in last 20 years. While manufacturing grew its added value by $3.6 \%$ and the world economy made it $2.8 \%$, construction only did so at 1\% (World Economic Forum, October 25, 2018). 
(2014), techniques from the automotive sector such as concurrent engineering, value engineering, benchmarking and balance lines have been incorporated quickly to manage the integration of information with production cycles.

However, tools as such are not everything. From another point of view Hackler (2017) exposes the importance of building a lean culture in organizations and selecting teams that really want to adopt lean, because accelerating the understanding and implementation of lean in a company is based on change management. Also the lean team requires the support of management at all levels from training the workers on practical tools to educating them on the lean principles as a general way to execute their projects.

\section{RESEARCH METHOD}

As a first instance, the state of the art of lean construction and some lean thinking tools used worldwide in the housing construction sector were reviewed, finding that there are different practices, including own ones, that have been developed in this sector to meet the needs of this industry.

Subsequently, the selected articles were classified reviewing whether they mentioned the implementation of a lean tool in a success case; in addition, the author or authors were taken into account, the country in which it was developed and the year of publication.

Consecutively after this classification, the results were recorded in a database and the affinity analysis was generated and then the Pareto chart.

To describe the system, the Mayring methodology (2014) entitled Qualitative Content Analysis was used ${ }^{8}$, starting with the selection of the object of analysis, the linking of the research question with the theory; the development of the pre-analysis through the bibliographic consultation of experts, identifying the lean tools used in the construction field; the definition of the sample and the method of data analysis by means of an affinity and Pareto analysis; and the analysis of the coherence of the study carried out.

\section{SEARCH FOR EXPERTS}

Based on the referential framework, which allowed dimensioning the variety of existing concepts related to lean construction, a search of sources related to this topic was made in order to know which lean tools are used in this sector.

This consultation provided the necessary information to recognize the particular conditions that the system to study can have and the environment in which it is immersed, also defining the primary guidelines for classification of the tools, as well as finding a large number of lean tools common to several authors about the focus of study.

Knowledge gathering was done taking secondary sources of information from experts, understood them as the authors who document information on the factors directly or indirectly related to this problem, that is, their publications and opinions, expressed mainly in research articles, by national and international authors.

8 The central idea of qualitative content analysis is to start from the methodological basis of quantitative content analysis but conceptualizing the process of assigning categories as a qualitativeinterpretative act following content analytical rules. In this sense, qualitative content analysis is a mixed methods approach: assignment of categories as a qualitative step and analysis of the frequencies of categories as a quantitative step. 
84 documents between nationals and foreigners were consulted, majority of them were published on the website of the International Group for Lean Construction (IGLC) in the last five years (in this article only 23 references are presented). This database presents a complete collection of lean construction publications, so this was the main reason to select it as the prevailing source for this research. From these documents, a total of 254 mentions of lean thinking and lean construction tools were obtained, which were categorized by means of affinity in 23 selected causes according to relevance and being the most named by the experts.

The nationality of these authors is concentrated in twenty-two countries as shown in table 1. However, the most representative countries are Germany (Dlouhy, et al., 2017), Brazil (Franco and Picchi, 2016), Chile (Salvatierra, et al., 2015; Matta, et al., 2018), United States (Smith and Ngo, 2017; Alves, Azambuja and Arnous, 2016), India (Patel, Karia and Pandit, 2018), England (Tezel, et al., 2016) and Norway (Torp, Knudsen and Ronneberg, 2018). Other authors consulted came from Australia (Shou, et al., 2017), Ecuador (Martínes, Tommelein and Alvear, 2017), Estonia (Leonova, Ballard and Gehbauer, 2017), Finland (Singh, 2018), Ireland (Kemmer, et al., 2016), Lebanon (Hatoum, et al., 2018), Morocco (Hicham, Taoufiq and Aziz, 2016), Mexico (Dlouhy, et al., 2018), New Zealand (Hunt and Gonzalez, 2018), Netherlands (Vrijhoef, Dijkstra and Koutamanis, 2018), Peru (Murguía, Brioso and Pimentel, 2016), Palestine (Enshassi and Abu Zaiter, 2014), South Africa (Monyane, Emuze and Crafford, 2018) and Pakistan (Memon, et al., 2018).

Table 1. Characteristics of the experts consulted by geographic context

\begin{tabular}{|c|c|c|}
\hline Country & $\begin{array}{c}\text { Number of experts from } \\
\text { the country }\end{array}$ & Percentage of experts \\
\hline Germany & 5 & $5,95 \%$ \\
\hline Australia & 1 & $1,19 \%$ \\
\hline Brazil & 15 & $17,86 \%$ \\
\hline Chile & 9 & $10,71 \%$ \\
\hline Colombia & 5 & $5,95 \%$ \\
\hline Ecuador & 1 & $1,19 \%$ \\
\hline United States & 12 & $14,29 \%$ \\
\hline Estonia & 1 & $1,19 \%$ \\
\hline Finland & 1 & $1,19 \%$ \\
\hline India & 7 & $8,33 \%$ \\
\hline England & 5 & $5,95 \%$ \\
\hline Ireland & 1 & $1,19 \%$ \\
\hline Lebanon & 4 & $4,76 \%$ \\
\hline Morocco & 1 & $1,19 \%$ \\
\hline Mexico & 1 & $1,19 \%$ \\
\hline Norway & 8 & $9,52 \%$ \\
\hline New Zealand & 1 & $1,19 \%$ \\
\hline Netherlands & 1 & $1,19 \%$ \\
\hline Pakistan & 1 & $1,19 \%$ \\
\hline Palestine & 1 & $1,19 \%$ \\
\hline Peru & 1 & $1,19 \%$ \\
\hline South Africa & 2 & $2,38 \%$ \\
\hline Total & 84 & $100 \%$ \\
\hline
\end{tabular}

Nearly $6 \%$ of the authors consulted are Colombians (Forero, et al., 2015, Mejía, et al., 2016, Cortés, et al., 2018, Porras, Sánchez and Galvis, 2014, Guevara, et al., 2011). Of the remaining experts consulted, 31\% are from Latin American countries, 26\% are 
European, 61\% North American, 15\% Asian, 4\% come from African countries and the remaining $2 \%$ are from Oceania. This variety allows a greater proximity to the landscape of lean construction developed in Colombia and surrounding countries. Figure 1 shows a description of the nationality of the authors consulted.

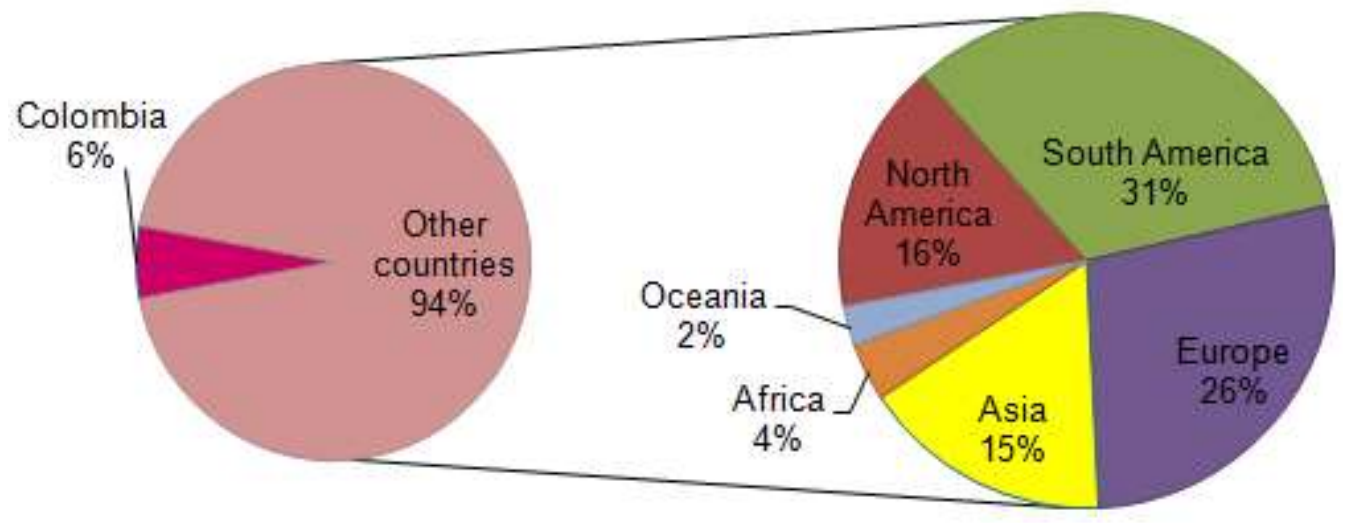

Figure 1. Nationality of the authors

Regarding the age of the documents reviewed, Table 2 shows that more than $97 \%$ of the information was prepared less than five years ago, and that was an aspect of interest in the search given that the objective is to review the current trends in lean construction. However, two articles presented at IGLC conferences, prepared in 2011 and 2013, of Colombian and Brazilian origin respectively, were reviewed because there are not many Colombian papers presented in IGLC and all those from Colombia that could provide information of interest to this investigation were reviewed.

Table 2. Characteristics of the sources by nationality and age of the publication

\begin{tabular}{ccc}
\hline Characteristic & Total & Percentage \\
\hline Colombian authors & 5 & $5,95 \%$ \\
Foreign authors & 79 & $94,05 \%$ \\
Sources of up to 5 years & 82 & $97,62 \%$ \\
Sources over 5 years & 2 & $2,38 \%$ \\
\hline
\end{tabular}

\section{AFFINITY ANALYSIS}

After reviewing and consolidating the 30 lean tools, the affinity analysis was carried out, by means of which these tools were classified into 23 categories, seeking to concentrate in the same group those that had similarities or that some authors expressed that they were related to others (see Table 3).

For example, according to the Lean Construction Institute (LCI) (2017), Building Information Modeling (BIM) is a useful tool for the process of generation and management of data during the life cycle of a project (building) that includes geometry of construction, spatial relations, geographic information, quantities and properties of building components, among others. But taking into account that BIM uses a threedimensional dynamic building modeling software (3D) and that can also include fourdimensional (4D) simulations to see how part or all of the installation is designed to be built and the 5D capacity for estimation based on models, in this category the BIM and 4D BIM tools mentioned separately by some authors were included (See Table 3).

Table 3. Proposed affinity of lean tools 


\begin{tabular}{cc}
\hline Initial category & Fine-tuned lean tool \\
\hline $\begin{array}{c}\text { Building Information models (BIM) } \\
\text { 4D Building Information Modeling (BIM) }\end{array}$ & Building Information models (BIM) \\
\hline $\begin{array}{c}\text { Choosing by Advantages (CBA) } \\
\text { Best Value Procurement (BVP) }\end{array}$ & Choosing by Advantages (CBA) \\
\hline Waste walk & Gemba walk \\
Gemba & Value Stream Mapping (VSM) \\
\hline $\begin{array}{c}\text { Value Stream Mapping (VSM) } \\
\text { Overall Process Analysis (OPA) }\end{array}$ & Visual Management (VM) \\
\hline $\begin{array}{c}\text { Visual Management } \\
\text { Poka Yoke }\end{array}$ & \\
Customization choice board \\
Display boards
\end{tabular}

In the same way, the resulting category Choosing by Advantages (CBA) groups the Choosing by Advantages (CBA) and Best Value Procurement (BVP) tools. According to LCI glossary (2017), CBA is a solid, proven and effective decision-making system developed by Jim Suhr in 1999 to determine the best decision when analyzing the benefits of each option. Regarding the Best Value Procurement (BVP), Narmo, Wondimu and Laedre (2018) state that it is a procurement system created in 1992 that analyzes factors other than price, such as quality and experience, when selecting suppliers or contractors. This method was developed in the United States and is one of the ways to award contracts based on qualification instead of the price.

On the other hand, as stated by the LCI (2017), Gemba is a Japanese term for "real place", which is often used for the workshop or any place where a work of value creation actually takes place. The lean experts refer to "going to the gemba" or doing a "gemba walk" to make walks in the workplace and see how things really are done and where there is an opportunity to eliminate or reduce waste. Similarly, other authors such as Beck da Silva Etges, Bronzatto and Salgado (2018) refer to the same concept with the term "waste walk", so for purposes of this work are grouped in the category "gemba walk".

In Lean Lexicon (2008), the Value Stream Mapping is a simple diagram of each step involved in the flows of material and information necessary to carry a product from the order to the delivery in the current conditions. In the study by Theis, Tommelein and Emdanat (2017) the General Process Analysis (OPA) refers to a one-time analysis that aims to identify the different areas of work and define the steps of the process and the sequence of operations in each area. Since these two tools have the same purpose, they are grouped in the same category in this research.

As mentioned by the Lean Enterprise Institute (2008), Visual Management refers to the location at a glance of all the tools, parts, production activities and performance indicators of the production system, so the state of the system can be understood at a glance by all the parties involved. Reviewing the consulted publications, several authors mention different visual management tools such as Poka Yoke, visualization boards and personalization tools to name some visual management tools implemented in different contexts, which based on their nature, can be categorized into a single tool: Visual Management.

Finally Etges, Pereira and Silveira (2018) mention "Chrono Analysis" as a tool that consists of an uninterrupted time of filming during a long period (minimum of 4 hours) 
to observe the level of added value in complete cycles of activities. On the other hand Pothen and Ramalingam (2018) mention the "Work sampling" that consists of a series of instantaneous observations of the work in progress that are taken at random over a period of time to measure productivity. This method provides information on the amount of time that workers spend doing productive, supportive and non-productive work. Therefore, they are grouped into a category called "Work sampling".

\section{PARETO ANALYSIS}

The Pareto analysis consists in organizing the lean tools in a descending manner depending on the frequency of mention by the experts consulted. By ordering each of the 23 categories according to the number of appearances, the relative frequency was calculated against the total of 254 records and the accumulated frequency. Table 4 shows the ordering and the tools enunciated by the authors.

Table 4. Lean tools most named by the experts

\begin{tabular}{|c|c|c|c|c|}
\hline Fine-tuned lean tool & $\begin{array}{l}\text { Frequenc } \\
\qquad y\end{array}$ & $\begin{array}{l}\text { Accumulate } \\
\text { d frequency }\end{array}$ & $\%$ total & $\begin{array}{c}\% \text { total } \\
\text { accumulate } \\
\text { d }\end{array}$ \\
\hline Last Planner® System (LPS) & 46 & 46 & $\begin{array}{c}18,11 \\
\%\end{array}$ & $18,11 \%$ \\
\hline Building Information Models (BIM) & 41 & 87 & $\begin{array}{c}16,14 \\
\%\end{array}$ & $34,25 \%$ \\
\hline Visual management (VM) & 26 & 113 & $\begin{array}{c}10,24 \\
\%\end{array}$ & $44,49 \%$ \\
\hline Value Stream Mapping (VSM) & 17 & 130 & $6,69 \%$ & $51,18 \%$ \\
\hline Target Value Design (TVD) & 16 & 146 & $6,30 \%$ & $57,48 \%$ \\
\hline $5 S$ & 16 & 162 & $6,30 \%$ & $63,78 \%$ \\
\hline Integrated Project Delivery (IPD) & 14 & 176 & $5,51 \%$ & $69,29 \%$ \\
\hline Choosing by Advantages (CBA) & 13 & 189 & $5,12 \%$ & $74,41 \%$ \\
\hline Kanban & 12 & 201 & $4,72 \%$ & $79,13 \%$ \\
\hline $\begin{array}{l}\text { Takt Planning and Takt Control } \\
\text { (TPTC) }\end{array}$ & 8 & 209 & $3,15 \%$ & $82,28 \%$ \\
\hline A3 report & 8 & 217 & $3,15 \%$ & $85,43 \%$ \\
\hline Andon & 5 & 222 & $1,97 \%$ & $87,40 \%$ \\
\hline Set-Based Design (SBD) & 5 & 227 & $1,97 \%$ & $89,37 \%$ \\
\hline Gemba walk & 5 & 232 & $1,97 \%$ & $91,34 \%$ \\
\hline Just in Time (JIT) & 4 & 236 & $1,57 \%$ & $92,91 \%$ \\
\hline Heijunka & 4 & 240 & $1,57 \%$ & $94,49 \%$ \\
\hline Work Sampling (WS) & 4 & 244 & $1,57 \%$ & $96,06 \%$ \\
\hline RFID & 2 & 246 & $0,79 \%$ & $96,85 \%$ \\
\hline 5 Whys & 2 & 248 & $0,79 \%$ & $97,64 \%$ \\
\hline Jidoka & 2 & 250 & $0,79 \%$ & $98,43 \%$ \\
\hline Value Engineering & 2 & 252 & $0,79 \%$ & $99,21 \%$ \\
\hline Modelo Means - End & $\overline{1}$ & 253 & $0,39 \%$ & $99,61 \%$ \\
\hline SMED & 1 & 254 & $0,39 \%$ & $100,00 \%$ \\
\hline Total & 254 & & & \\
\hline
\end{tabular}

With this analysis it can be seen that the nine lean tools that represent $80 \%$ of all tools are Last Planner System ${ }^{\circledR}$, Building Information Models, Visual Management, Value Stream Mapping, Target Value Design, 5S, Integrated Project Delivery, Choosing by Advantages and Kanban, adding 201 mentions of the total 254. 
In Figure 2 the Pareto chart is presented with the ordered categories of Table 4 on the horizontal axis and the absolute and relative frequencies on the vertical axes, the trend line shows the accumulation of the opinions given by the experts.

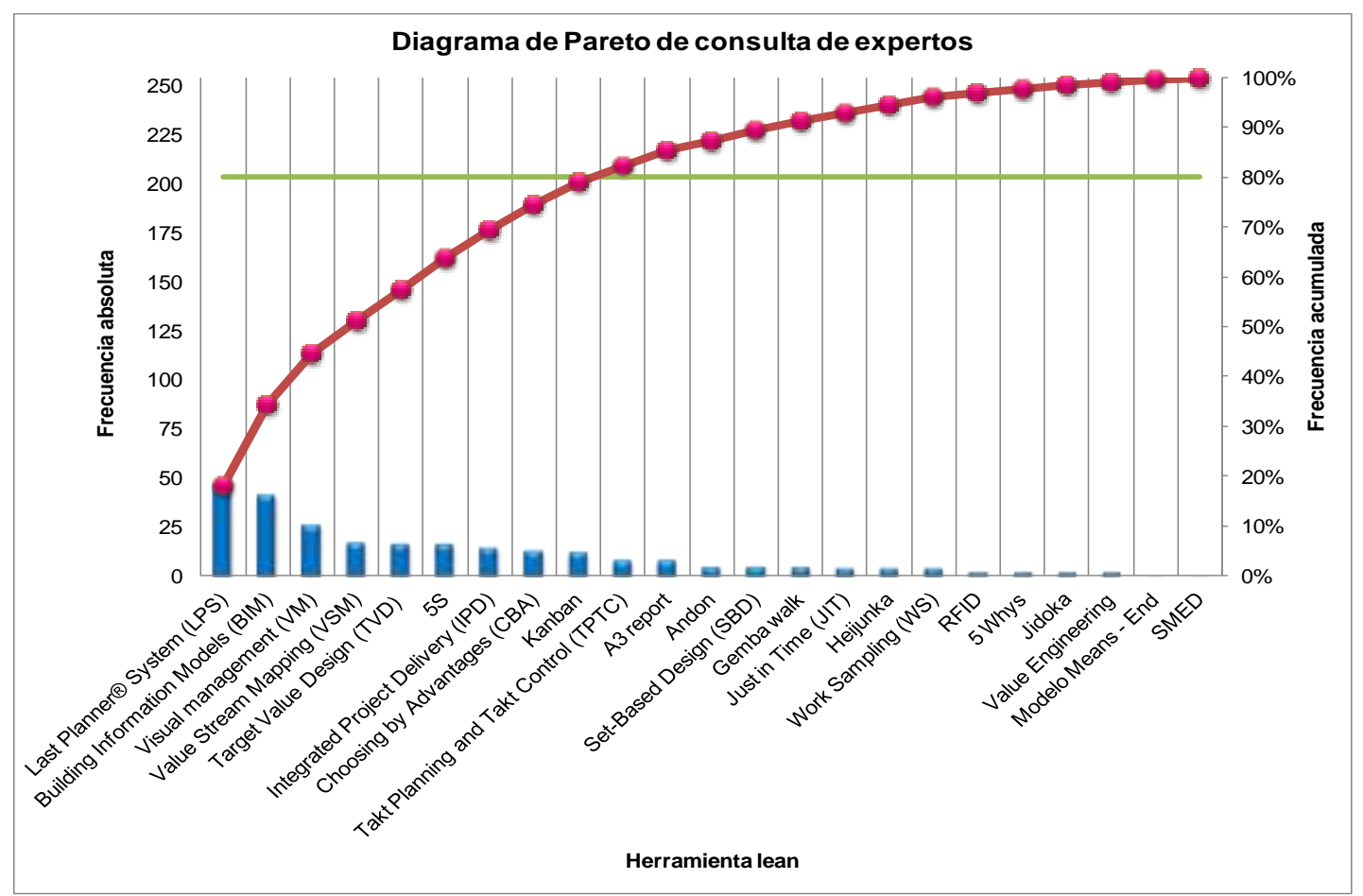

Figure 2. Pareto chart.

All these lean tools must be taken into account when proposing the global tool of lean construction in construction of housing in Colombia, because it has been evidenced, by experience in the sector, not even the basic tools such as 5 Whys, $5 \mathrm{~S}$, A3 report, Heijunka, are well implemented or even have a minimal idea of how to practice them.

It is worth mentioning that the Last Planner System requires a certain level of lean understanding in order to be properly implemented, especially since multiple stakeholders are involved in this method. Considering that in Colombia the level of understanding and application of lean construction is not very widespread, it is important to start with an organizational change management and continuous training that implies the introduction of basic lean methods which would be a good start with raising lean awareness and pave the way to adopt the findings of this paper, specifically, the last planner system as a global guiding tool to resolve the gap addressed.

\section{CONCLUSIONS}

Lean construction is an application of lean thinking. It requires a change of philosophy in the construction companies and in the relation with suppliers and clients for the tools to be effective. Additionally it needs a change of culture and strong commitment from all stakeholders at medium term for the assimilation and application of the concept.

Hence, lean construction should not be conceived as a model or system in which only a few steps are followed, but as a thought aimed at the creation of tools that generate value for the activities, phases and stages of construction projects. 
Although lean construction reduces operating costs, increases economic benefits, reduces material waste and improves the productivity and quality of life of people working in the construction industry, in Colombia the use of this tool has not taken off properly, remaining in practices developed in single projects on an experimental basis without any transcendence or reproducibility of its results.

Conventional construction in Colombia differs from lean thinking in the planning and execution of civil works, with only a few companies implementing this philosophy of work due to the industry still settles on many craft processes with a high level of inefficiency.

In Latin America, Brazil and Chile are the countries that have excelled in the development of advanced technologies to improve productivity in the construction sector. Of the 84 studies reviewed, only $6 \%$ are of Colombian origin and $37 \%$ of the total of authors is from Latin American. Lean construction represents an opportunity for the sector to take advantage of the benefits that have been evident in other countries.

The Last Planner System ${ }^{\circledR}$ is the most used lean tool for the planning of works through the use of balance lines as a tool for visualizing the master plan and weekly meetings and daily walks. It is convenient to review the functionality and use of other tools in order to obtain improvements in the construction processes.

To stay in the market, construction companies must improve the organization of their processes, maximizing value and reducing waste through the application of lean construction. Companies are realizing the importance of incorporating this philosophy in organizations, guiding the purchase of software and looking for management systems that already have the methodology incorporated.

\section{REFERENCES}

Alves, T.D.C.L., Azambuja, M.M. and Arnous, B. (2016). "Teaching Lean Construction: A Survey of Lean Skills and Qualifications Expected by Contractors and Specialty Contractors in 2016". Proc. of the 24th Ann. Conf. of the Int'l Group for Lean Construction. Boston, USA.

Araque, G., García, D., and Aguirre, E. (2017). "The Lean Construction methodology and the analysis of losses in the Colombian civil sector: A case study". Actas de Ingeniería. Colombia. (3). 213-221 (in spanish).

Botero, L., Álvarez, M. (2004). "Guía de mejoramiento continuo para la productividad en la construcción de proyectos de vivienda (Lean construction como estrategia de mejoramiento)". Revista Universidad EAFIT. Colombia. 40 (136). 50-64 (in spanish).

Colombian Association of Systems Engineers (2019). "La Importancia de adoptar el Lean Construction”. <https://acis.org.co/portal/content/la-importancia-de-adoptarel-lean-construction> (Apr 20, 2019).

Cortes, J.P.R., Ponz-Tienda, J.L., Delgado, J.M. and Gutierrez-Bucheli, L. (2018). "Choosing by Advantages; Benefits Analysis and Implementation in a Case Study, Colombia". Proc. of the 26th Ann. Conf. of the Int'l Group for Lean Construction. Chennai, India.

Dlouhy, J., Binninger, M., Weichner, L. and Haghsheno, S. (2017). "Implementation of Lean Construction in Client Organizations - an Analysis of the Status Quo in Germany". Proc. of the 25th Ann. Conf. of the Int'l Group for Lean Construction. Heraklion, Greece. 
Dlouhy, J., Ricalde, M., Cossio, B. and Januncio, C. (2018). "Large Scale Project Using Takt Planning and Takt Control-Creating and Sustaining Multitasking Flow". Proc. of the 26th Ann. Conf. of the Int'l Group for Lean Construction. Chennai, India.

Enshassi, A. and Abu Zaiter, M. (2014). "Implementation of Lean Tools on Safety in Construction Projects in Palestine" In:, Kalsaas, B.T., Koskela, L. and Saurin, T.A. Proc. of the 22th Ann. Conf. of the Int'l Group for Lean Construction. Oslo, Norway.

Etges, B.M.B.D.S., Pereira, B.B. and Silveira, T.J.S.D. (2018). "A Lean Approach to Improve Productivity in a Coke Oven Refurbishment Project: A Case Study". Proc. of the 26th Ann. Conf. of the Int'l Group for Lean Construction. Chennai, India.

Forero, S., Cardenas, S., Vargas, H. and Garcia, C. (2015). "A Deeper Look Into the Perception and Disposition to Integrated Project Delivery (IPD) in Colombia" In:, Seppänen, O., González, V.A. and Arroyo, Proc. of the 23th Ann. Conf. of the Int'l Group for Lean Construction. Perth, Australia.

Franco, J.V. and Picchi, F.A. (2016). "Lean Design in Building Projects: Guiding Principles and Exploratory Collection of Good Practices". Proc. of the 24th Ann. Conf. of the Int'l Group for Lean Construction. Boston, USA.

Guevara, J., Ozuna, A., Vargas, H., Prieto, J. and Ramirez, C. (2011). "Promoting Innovation in a Colombian Social Housing Construction Company" In:, Rooke, J. and Dave, B., Proc. of the 25th Ann. Conf. of the Int'l Group for Lean Construction. Lima, Peru.

Hackler, C., Byse, E., Reed, D. and Alves,T.D.C. (2017). "Building a Lean Culture". Proc. of the 25th Ann. Conf. of the Int'l Group for Lean Construction. Heraklion, Greece.

Hatoum, M.B., Mustapha, R.E., Nassar, C., Zaheraldeen, H. and Hamzeh, F. (2018). "Lean Methods to Improve End User Satisfaction in Higher Education Buildings". Proc. of the 26th Ann. Conf. of the Int'l Group for Lean Construction. Chennai, India.

Hicham, H., Taoufiq, C. and Aziz, S. (2016). "Last Planner® System: Implementation in a Moroccan Construction Project". Proc. of the 24th Ann. Conf. of the Int'l Group for Lean Construction. Boston, USA.

Hunt, R.J. and Gonzalez, V.A. (2018). "Innovation in the New Zealand Construction Industry - Diffusion of the Last Planner System". Proc. of the 26th Ann. Conf. of the Int'l Group for Lean Construction. Chennai, India.

Kemmer, S., Biotto, C., Chaves, F., Koskela, L. and Fazenda, P.T. (2016). "Implementing Last Planner in the Context of Social Housing Retrofit". Proc. of the 24th Ann. Conf. of the Int'l Group for Lean Construction. Boston, USA.

Lean Construction Institute. (2017). LCI Lean Project Delivery Glossary. $<$ https://www.leanconstruction.org/learning/education/glossary/> (05Dec18).

Lean Enterprise Institute (2008). Lean Lexicon. A graphical glossary for lean thinkers. Fourth edition. USA.

Leonova, M., Ballard, G. and Gehbauer, F. (2017). "Strategies That Can Help Transform the Construction Industry". Proc. of the 25th Ann. Conf. of the Int'l Group for Lean Construction. Heraklion, Greece.

Martinez, E., Tommelein, I.D. and Alvear, A. (2017). "Integration of Lean and Information Technology to Enable a Customization Strategy in Affordable 
Housing". Proc. of the 25th Ann. Conf. of the Int'l Group for Lean Construction. Heraklion, Greece.

Matta, G., Herrera, R.F., Baladrón, C., Giménez, Z. and Alarcón, L.F. (2018). "Using BIM-Based Sheets as a Visual Management Tool for on-Site Instructions: A Case Study". Proc. of the 26th Ann. Conf. of the Int'l Group for Lean Construction. Chennai, India.

Mayring, P. (2014). "Qualitative content analysis: theoretical foundation, basic procedures and software solution". Social Science Open Access Repository. Austria. <https://nbn-resolving.org/urn:nbn:de:0168-ssoar-395173> (02Dec18).

Mejía-Plata, C., Guevara-Ramirez, J.S., Moncaleano-Novoa, D.F., Londoño-Acevedo, M.C., Rojas-Quintero, J.S. and Ponz-Tienda, J.L. (2016). "A Route Map for Implementing Last Planner® System in Bogotá, Colombia". Proc. of the 24th Ann. Conf. of the Int'l Group for Lean Construction. Boston, USA.

Memon. A., Akhund M., Laghari A., Imad H., and Bhangwar S. (2018). "Adoptability of Lean Construction Techniques in Pakistan's Construction Industry". Civil Engineering Journal. Irán. 4(10). 2328-2337.

Monyane, T.G., Emuze, F.A. and Crafford, G. (2018). "Identification of Lean Opportunities in a South African Public-Sector Projects Cost Management Framework". Proc. of the 26th Ann. Conf. of the Int'l Group for Lean Construction.Chennai, India.

Murguía, D., Brioso, X. and Pimentel, A. (2016). "Applying Lean Techniques to Improve Performance in the Finishing Phase of a Residential Building". Proc. of the 24th Ann. Conf. of the Int'l Group for Lean Construction. Boston, USA.

Narmo, M., Wondimu, P., and Lædre, O. (2018). "Best Value Procurement (BVP) in a Mega Infrastructure Project". Proc. of the 26th Ann. Conf. of the Int'l Group for Lean Construction. Chennai, India.

Newspaper El Constructor (2017). "Lean Construction: ¿Una nueva tendencia en construcción eficiente?". < https://www.elconstructor.com/lean-construction-unanueva-tendencia-en-construccion-eficiente_4671.html> (Oct, 27, 2017).

Patel, V.V., Karia, N. and Pandit, D. (2018). "Identifying Value Enhancing Factors and Applicability of Visual Management Tools". Proc. of the 26th Ann. Conf. of the Int'l Group for Lean Construction. Chennai, India.

Pons, J. (2014). "Introducción a Lean Construction”. Fundación Laboral de la Construcción. España. Vol. 1.

Porras, H., Sánchez, O., Galvis, J. (2014). "Filosofía Lean Construction para la gestión de proyectos de construcción: una revisión actual". Journal Avances. Investigación en Ingeniería. Colombia. 11 (1). 32-53 (in spanish).

Pothen, L.S. and Ramalingam, S. (2018). "Applicability of Value Stream Mapping and Work Sampling in an Industrial Project in India". Proc. of the 26th Ann. Conf. of the Int'l Group for Lean Construction. Chennai, India.

Revista Dinero. (2018). "Auguran buen futuro para el sector de la construcción en Colombia".<https://www.dinero.com/edicion-impresa/informeespecial/articulo/perspectivas-del-sector-de-la-construccion-en-colombia2018/259814> (Jul. 5, 2018).

Rojas, M., Henao, M., and Valencia, M. (2017). "Lean construction - LC bajo pensamiento Lean". Revista Ingenierías Universidad de Medellín. Colombia. 16 (30). 115-128 (in spanish). 
Salvatierra, J.L., Alarcón, L.F., López, A. and Velásquez, X. (2015). "Lean Diagnosis for Chilean Construction Industry: Towards More Sustainable Lean Practices and Tools". In:, Seppänen, O., González, V.A. and Arroyo, P., Proc. of the 23th Ann. Conf. of the Int'l Group for Lean Construction. Perth, Australia.

Shou, W., Wang, J., Wu, P., Wang, X. and Song, Y. (2017). "Application of Lean Production With Value Stream Mapping to the Blasting and Coating Industry". Proc. of the 25th Ann. Conf. of the Int'l Group for Lean Construction. Heraklion, Greece.

Singh, V. (2018). "Towards Creative Lean (Clean) Construction: From Lean Production to Lean Consumption". Proc. of the 26th Ann. Conf. of the Int'l Group for Lean Construction. Chennai, India.

Smith, J.P. and Ngo, K. (2017). "Implementation of Lean Practices Among Finishing Contractors in the US". Proc. of the 25th Ann. Conf. of the Int'l Group for Lean Construction. Heraklion, Greece.

Tezel, A., Aziz, Z., Koskela, L. and Tzortzopoulos, P. (2016). "Visual Management Condition in Highways Construction Projects in England". Proc. of the 24th Ann. Conf. of the Int'l Group for Lean Construction. Boston, USA.

Theis, P., Tommelein, I. and Emdanat, S. (2017). Use of Takt Planning in Production System Design. Workshop on Takt Planning. UC Berkeley. <https://www.leanconstruction.org/?s=Use+of+Takt+Planning+in+Production+Sy stem+Design> (Sep 26, 2017).

Torp, O., Knudsen, J.B. and Rønneberg, I. (2018). "Factors Affecting Implementation of Lean Construction". Proc. of the 26th Ann. Conf. of the Int'l Group for Lean Construction. Chennai, India.

Vrijhoef, R., Dijkstra, J.T. and Koutamanis, A. (2018). "Modelling and Simulating Time Use of Site Workers With 4D BIM". Proc. of the 26th Ann. Conf. of the Int'l Group for Lean Construction. Chennai, India.

World Economic Forum. (2018). Incrementemos la productividad en la construcción en Latinoamérica. <https://es.weforum.org/agenda/2018/10/incrementemos-laproductividad-en-la-construccion-en-latinoamerica/>. (Oct. 25, 2018). 
Castiblanco, F, M., Castiblanco, I, A., Cruz, J. P 